\title{
Revision and Validation of the Family Apperception Test: Some Psychometric Properties
}

The Family Journal: Counseling and Therapy for Couples and Families 18(3) 297-309

(C) 2010 SAGE Publications

DOI: $10.1177 / 1066480710372086$

http://tfj.sagepub.com

(S)AGE

\author{
Isabelle Roskam', Marie Stiévenart', Laurence Deschuyteneer', and \\ Susann Heenen-Wolff'
}

\begin{abstract}
The Family Apperception Test (FAT) is a projective assessment procedure based on the family system theory. FAT allows the subjects' affects and feelings about their family to be assessed. The original version and its French translation removed some of the conceptual and psychometric limitations of previous projective tests and family assessment procedures but several questions remained. The current study proposes several modifications to the conceptual background, administration, coding procedure, and standardization of the FAT, which considerably improve its psychometric properties. Data were collected on 168 typical and clinical children in the French-speaking part of Belgium. The results provide significant evidence for inter- and intra-assessor reliability; the factorial analysis and the internal consistency of the revised version were good; the FAT enabled us to discriminate between typical children and those in the clinical sample. The discussion focuses on the interest and limits of the quantitative coding procedure, based on several categories conceptualized as risk versus protective factors. The FAT is characterized by a complementary approach — both quantitative and qualitative - to the children and their families.
\end{abstract}

\section{Keywords}

projective assessment, family system theory, validation

The Family Apperception Test (FAT) was originally published by Sotile, Julian, Henry, \& Sotile, in 1988, with a French translation in 1999. FAT is an original and recent projective assessment procedure based on the family system theory. In psychoanalytic theory, the projection is a defense mechanism whereby the subject transfers or attributes his feelings or traits onto another person or object; the projection mechanism preserves the unconscious content of feelings by exporting them (Anderson \& Anderson, 1965). Using nonsignificant material or pictures, projective assessment procedures lead the subjects to express affects and feelings. FAT allows the subjects' affects and feelings about their family to be assessed. It can be identified as an interpretative method (Eysenck, 1955; Zubin, Eron, \& Schumer, 1965) or a thematic projective test (Anzieu \& Chabert, 1999) within the field of family assessment procedures. The original version of FAT overcame some of the conceptual and psychometric limitations of both previous projective tests and family assessment procedures (as discussed below). Some questions, however, remain. The current research stresses the benefits and weaknesses of the original version of FAT. It then proposes several modifications in the conceptual background, the administration, the coding procedure, and the standardization of the test. These modifications should improve its psychometric properties.

\section{Previous Tests \\ Projective Tests}

Most interpretative or thematic projective tests were published between 1920 (e.g., the Rorschach test, Rorschach, 1921) and 1970 (e.g., the Thematic Apperception Test [TAT] by Murray, 1943; the Children's Apperception Test by Bellak \& Bellak, 1949). Although the theoretical framework of these was well documented in psychoanalytic literature, they sometimes suffered from a lack of guidelines for the marking and the interpretation of the subject's responses. Despite important work made by authors like for example Weiner $(2000,2003)$ to improve guidelines for enhancing the quality and use of the interpretation of projective tests, they cannot easily be used for clinical research. Furthermore, it is rare for them to have been standardized on a broad-ranging sample. Thus, they do not allow the "normality" of the subjects' responses to be assessed in

\footnotetext{
${ }^{I}$ Catholic University of Louvain, Belgium

Corresponding Author:

Isabelle Roskam, Department of Psychology, Catholic University of Louvain, 10 Place du Cardinal Mercier, I348 Louvain-La -Neuve, Belgium

Email: isabelle.roskam@psp.ucl.ac.be
} 
relation to their age, gender, or educational level for example. In addition, due to inherent difficulty in validating projective assessment procedures, rare were the studies focusing on their psychometric properties - reliability and validity - Existing empirical studies usually concerned the TAT (Murray \& Bellak, 1943) or the Rorschach test (Rorschach, 1921), whereas psychometric information is unavailable for most other projective tests. Donleavy and Lim (1990) tried to confirm the crosscultural validity of the TAT. Meta-analyses have questioned the validity of the Rorschach test (Garb, Florio, \& Grove, 1998; Gronnerod, 2003; Parker, 1983; Parker, Hanson, \& Hunsley, 1988), finding low coefficients of validity and reliability, and a low percentage of explained variance. The results also suggest that the psychometric properties may vary according to population and culture. As for reliability, Lisansky (1956) indicated that the inter-rater reliability of the Rorschach test was low whereas Grant, Ives, and Ranzoni (1952) and more recently Meyer, Mihura, and Smith (2005) reported satisfactory indices. Finally, a few studies have considered children and adolescents. Henry and Farley (1959) and Janson and Stattin (2003) used longitudinal designs and concluded that the TAT and the Rorschach test were valid assessment procedures for predicting adolescents' delinquency. The Rorschach test was, however, not a valid predictor of depression in adolescence (Ball, Archer, Grodon, \& French, 1991; Carter \& Dacey, 1996).

\section{Family Assessment Procedures}

Most family assessment procedures are based on the family system theory, such as the approaches by Moos, Minuchin, McMaster, Olson, and Beavers. We examined 19 tests published between 1965 and 1992 (e.g., Family Relations Test by Bene, 1965; Family Picture Test by Corman, 1970; Family System Test by Gehring \& Debry, 1992). They typically rely on questionnaires, indexes, inventories, Q-sorting, or material handling with clear guidelines for marking and interpreting subjects' responses. In addition to norms, validity and reliability indices are sometimes available. Test-retest correlations have been computed for 12 of the 19 tests and vary between .42 (Family System Test by Gehring \& Debry, 1992) and .90 (Structural Family Interaction Scale by Perosa, Hansen, \& Perosa, 1981). Cronbach's $\alpha$ s are available for 9 of the 19 tests and range from .60 (Family Assessment Measure by Skinner, Steinhauer, \& Santa-Barbara, 1983) to .93 (Self-Report Family Inventory by Beavers, Hampson, \& Hulgus, 1985), whereas norms have been computed for 10 of the 19 tests over moderate ( $N=186$; Self-Report Family Inventory, Beavers et al., 1990) to large $(N=1289$; Family Environment Scale, Moos, \& Moos, 1986) samples. However, only 5 of the 19 tests are suitable for use with school-aged children (Family Picture, Corman, 1970; Family System Test, Gehring \& Debry, 1992; Family Interaction Q-sort, Gjerde, Block, \& Block, 1983; Family Attitudes Test, Jackson, 1952; Family APGAR, Smilkstein, 1978); the others are intended for adolescents or adults.

\section{Original Version of the FAT}

The FAT was identified as a recent projective assessment procedure within the field of family assessment. FAT also appeared to overcome some of the conceptual and psychometric limitations of other projective and family assessment. Compared with other projective tests, FAT provided clear guidelines for the marking and the interpretation of the subject's responses, psychometrical properties - fidelity and validity-were displayed in the manual, and several empirical studies have been conducted. Compared with other family assessment procedures, FAT proposed alternative method of data collection based on projection and was suitable for school-aged children as well as for adolescents.

In its original version (Sotile et al., 1999) and its French translation in 1999, the authors intended the 21 projective pictures to be used with children as young as 6 years. The pictures involved family situations, for example dinner, school work, misbehavior, daily routines, and play time. The guidelines for marking relied on four main concepts of the family system theory: conflict, conflict solving, limits, and relations (quality, boundaries, and circularity). Guidelines lead to hypotheses about family system functioning. Each of the 21 stories produced by the subject had to be analyzed by means of a coding manual which defined coding categories for the four main concepts. The total number of marks in each lead to a dysfunction score (DS). Authors reported five unpublished validation studies among children aged from 6 to 15, displaying behavioral or scholastic problems, and typically developing children. Gingrich (1999) and De Chatelet (1999) provided some evidence for inter-informant reliability, with Cohen's $K$ ranging from .24 to .76 in Gingrich's study and from .25 to .69 in De Chatelet's one. Studies by Lundquist (1999), Buchanan (1999), and Eaton (1999) have supported the validity of the FAT because it permitted them to discriminate between clinical and other samples using the number of marks in the "conflict" and "limits" categories. The French version of the FAT has been used in two published studies: Daure (2001) with psychotic adolescents and Geuzaine (2003) with young adults. Both of these confirmed that the FAT assessment procedure had both clinical and research interest.

Nevertheless, some questions remained concerning both its clinical use and its psychometric properties for research. The FAT was used as an assessment tool between 2000 and 2004 by professional psychologists in several Belgian services. Scientific meetings made appear important questions concerning the validity and fidelity of the FAT. First, projections using 21 pictures took more than an hour to administer, which could test the subject's willingness to collaborate, especially with young children. Eaton (1988) already mentioned this limitation and used a short version with only four pictures to discriminate clinical and typical samples. Second, the youngest children (the 6-year-olds) did not seem to be able to project from the pictures, saying nothing when the pictures were presented. Third, the inter-informant coefficients were moderate to low (with Cohen's $K$ lower than .50 ), which suggested that operational 
definitions of the coding categories were needed. Fourth, several significant responses from children and adolescents could not be located within the existing coding categories (e.g. who is setting limits or coalition between parents), which implied that the conceptual background needed to be further developed. Fifth, although 39 categories were provided in the coding grid, only 22 of them were used to compute the final DS. No clear justification for the exclusion of the other 17 , which mostly referred to positive aspects of family functioning, was given by the authors. Psychologists were often criticized for addressing mainly the disturbances and paying less attention to subjects' assets. Addressing both strengths and weaknesses was recommended by Weiner (2000) as an important guideline to generate accurate and useful interpretation in projective assessment procedures. Finally, despite the studies by Lundquist (1987), Buchanan (1987), and Eaton (1988), the original version of FAT did not provide any information about the frequency of the coding categories in broad-ranging samples. These questions led us to revise the French version of the FAT assessment procedure and to undertake a validation study of this revised version.

\section{Revised Version of FAT}

Because young children have a limited attention span, we reduced the administration time by selecting pictures according to their ability to induce responses from children and adolescents. Ten pictures were selected for children aged 8-11: 1/ dinner, 3/punishment, 6/putting away, 8/shopping, 12/school work, 13/bedroom, 15/play, 18/trip, 19/office, and 21/embrace. Twelve pictures were selected for adolescents between 12 and 15 years old: 1/dinner, 4/clothes, 5/living room, 6/ putting away, 7/stairs, $8 /$ shopping, $9 /$ kitchen, $12 /$ school work, 15/play, 18/trip, 19/office, and 21/embrace. Six pictures were eliminated due to their inappropriateness $(2 /$ stereo, representing a child with a long-playing record which has disappeared from the daily environment; 10/baseball and 14/ ball play, which refer to sports that are unknown by many French-speaking children in Belgium), or their age and gender stereotyping (i.e., 11/ night out, 16/keys of car, 17/make-up, and 20/mirror). Projections using 10 pictures for children took 13.64 minutes on average $(S D=4.97)$; projections using 12 pictures for adolescents took 12.41 minutes on average $(S D=4.60)$.

The coding manual was entirely reviewed. Additional coding categories were added, refining the conceptual framework. Operational definitions were provided for each of the coding categories. The coding categories were split into two subcategories: some were conceptualized as risk factors, whereas the others were conceptualized as protection factors according to the child's or adolescent's development. By summing all the marks for the risk-factor categories gave the DS, whereas summing all the marks for the protection factors yielded the wellfunctioning score (WFS). The minimum number of marks was 34 and the maximum was $97(M=57.38, S D=11.42)$.

Several categories were coded as risk factors. Risk factors are characteristics which may precede a psychopathology and increase its probability. Risk factors imply vulnerability because they decrease the adaptation capabilities of the subject (Bergeron \& Valla, 1997). Family Conflicts as well as their Negative Solving have previously been related to externalizing and internalizing problems in children and adolescents (Caya, 2002; Davies, 1996; Jenkins, Simpson, Dunn, Rasbash, \& O'Connor, 2005; Niggemeyer, 2001; Sigfusdottir, Farcas, \& Silver, 2004). Inappropriate Limits (for example through disengaged or inconsistent parenting) have also been related to externalizing and internalizing behavior in children and adolescents (Campbell, Pierce, Moore, \& Marakowitz, 1996; Jewel \& Stark, 2003; Rasmussen, 1995; Rodriguez, 2003). Fusion and disengagement are conceptualized as indicators of inappropriate distance or cohesion between family members. Fusion has been shown to be related to mood disorders (Jewell \& Stark, 2003) and externalizing behavior (Barber \& Buehler, 1996), whereas disengagement and lack of cohesion within the family have been associated with both externalizing and internalizing behavior (Cuffe, McKeown, Addy, \& Garrison, 2005; Niggemeyer, 2001). Negative Coalition is conceptualized as an alliance between two family members against a third one in a conflict situation. Mother-child negative coalitions have been correlated with externalizing behavior in children, whereas conjugal coalitions have been correlated with internalizing behavior in children (Mathijsen, Koot, Verhulst, De Bruyn, \& Oud, 1998). A closed system was coded when exchanges between family members and the external world were prohibited, and the negative emotion category was coded when subjects mentioned anger, anxiety, or sadness. The Content Dynamics category was coded when a set of themes (illness, separation and reunion, money) was mentioned at least twice by the subject or when a specific theme (i.e., death, divorce, severe illness) was mentioned.

Several categories were coded as protective factors. Protective factors are coping behaviors which are used by subjects when their development and well-being are threatened. They favor adaptation and decrease the potential bad effects of risk factors (Bergeron \& Valla, 1997). Positive solving in conflict situations has previously been related to family adjustment (Tucker, McHale, \& Crouter, 2003), emotional security in children (Davies, 1996), and social competence (Moritzen, 2003). Appropriate limits, for example through consistent and supportive parenting, have been linked to a variety of adaptive outcomes (adjustment, personality, temperament, and social and cognitive skills) in children (Aunola \& Nurmi, 2005; Steinberg, Lamborn, Darling, Mounts, \& Dornbusch, 1994). Support among family members has been found to be associated with positive mood and social competence (Branje, van Lieshout, van Aken, \& Haselager, 2004; Moritzen, 2003; Sigfusdottir et al., 2004). Positive coalition is conceptualized as an alliance between two family members to solve a situation, prepare a surprise, or keep a secret without any sort of opposition or threat to another family member. An opened system refers to families encouraging exchanges between members and the external world, whereas the positive emotion category was coded when subjects mentioned happiness, respect, or serenity. 
Table I. Grouping of the 48 Categories in 14 Variables With Means (standard deviations) of the Marks for the I20 Typical Children

\begin{tabular}{|c|c|c|c|c|c|}
\hline & \multicolumn{2}{|c|}{ Protective Factors } & \multicolumn{3}{|c|}{ Risk Factors } \\
\hline Positive limits & $6.70(2.99)$ & $\begin{array}{l}\text { From an adult } \\
\text { From a child }\end{array}$ & Negative outcomes & $2.55(1.97)$ & $\begin{array}{l}\text { Negative solving } \\
\text { No solving }\end{array}$ \\
\hline Support & $4.92(2.76)$ & $\begin{array}{l}\text { Maternal support } \\
\text { Paternal support } \\
\text { Sibling support } \\
\text { Conjugal support } \\
\text { External support }\end{array}$ & Conflicting agents & $7.39(2.34)$ & $\begin{array}{l}\text { Maternal conflicting agent } \\
\text { Paternal conflicting agent } \\
\text { Sibling conflicting agent } \\
\text { Conjugal conflicting agent } \\
\text { External conflicting agent }\end{array}$ \\
\hline Positive coalitions & $0.53(0.74)$ & $\begin{array}{l}\text { Mother-child coalition } \\
\text { Father-child coalition } \\
\text { Sibling coalition } \\
\text { Conjugal coalition }\end{array}$ & Negative coalitions & $0.37(0.67)$ & $\begin{array}{l}\text { Mother-child coalition } \\
\text { Father-child coalition } \\
\text { Sibling coalition } \\
\text { Conjugal coalition }\end{array}$ \\
\hline Positive emotions & $4.85(2.63)$ & $\begin{array}{l}\text { Happiness/satisfaction } \\
\text { Welcome/respect } \\
\text { Serenity/assurance } \\
\text { Other positive emotion }\end{array}$ & Negative emotions & $11.13(3.50)$ & $\begin{array}{l}\text { Sadness/depression } \\
\text { Anger/hostility } \\
\text { Fear/anxiety } \\
\text { Other negative emotion } \\
\text { Content dynamics }\end{array}$ \\
\hline WFS & $27.5 \mathrm{I}(7.20)$ & & DS & $31.20(9.37)$ & \\
\hline
\end{tabular}

Note. WFS = well-functioning score; DS = dysfunction score.

Social competence has been related to positive affect in children (Moritzen, 2003).

The coding grids for children and adolescents are presented in Appendices A and B. Due to the low number of marks in several subcategories (as also observed by Eaton, 1988 in the initial validation study), the 48 categories were grouped into 14 variables for the statistical analyses. The variables are listed in Table 1, which shows the means and standard deviations of the marks in each category for the 120 typical children and adolescents.

The results of the validation study of the revised version are presented below. Several psychometric properties are displayed: (a) the inter-informant and intra-informant reliability; (b) the factorial analysis of the FAT and the internal consistency of the coding categories; (c) some discriminative properties based on comparisons between clinical and broad-ranging samples.

\section{Method}

\section{Sample}

Data were collected in 2005 and 2006 from 168 participants aged 8-16 (from fourth to ninth grade in school), 100 boys and 68 girls. Some 33 were only children, 65 had one sibling, and 70 had two or more siblings; 45 were first children, 33 were second born, and 56 were the youngest in a family of at least three children (no information is available for 34 children). Of the 168 participants, 106 were living with both biological parents and 62 with only one of their biological parents. Among these, 37 still had frequent contact with the other biological parent whereas 25 did not.

Three groups were studied: 120 typical children and adolescents (20 in each school grade from fourth to ninth); 25 who had consulted clinical services for scholastic, behavioral, or emotional problems; and 23 who were living in clinical units for adolescents displaying behavioral and/or personality disorders. Each of the participants in the two clinical groups was matched with a typical participant by age and gender. Comparative analyses were performed on these two paired samples of 48 participants in each (total $=96$ participants).

\section{Data Collection}

The typical participants were assessed at school with the agreement of their parents and teachers. They came from eight regular schools in the French-speaking part of Belgium. Children and adolescents displaying scholastic, behavioral, or emotional problems were recruited at the Cliniques Universitaires Saint$L u c$ in Brussels in Belgium. The adolescents displaying behavioral and personality disorders were recruited at the Institut Louis-Marie in Thy-le-Château in Belgium. The FAT was administrated individually, and participants' responses were audio recorded. The initial instruction was "I will show you several pictures. They represent children/adolescents within their families. Could you tell me the story of what happens for each picture and how it may end? There is no good or bad story 
and it is important that you rely on your imagination. I will record all your stories because I want to remember them." Reluctant participants were encouraged with prompts such as "What is going on now/next?" or "Tell me more about this family." Audio recording allowed two independent coders to apply the coding rules so that inter- and intra-coder reliability could be computed.

\section{Results}

\section{Inter- and Intra-Coder Reliability}

Inter-coder reliability was estimated with two independent coders over $10 \%$ of the total sample. Sixteen participants were selected at random from the total sample. The correlations between the two independent coders were high, $r=.91$ for WFS and $r=.98$ for DS. Allowing for the complexity of the coding process, Cohen's $K$ was also high, at .96 .

Intra-coder reliability was estimated on $20 \%$ of the total sample. Sixteen participants were selected at random by each of the two independent coders. Each of them coded the response of their 16 participants twice, with a six-month interval between codings. The correlations between the two ratings by coder A were very high $(r=.92$ for WFS and $r=.99$ for DS); Cohen's $K$ was also very high (at .98). The correlations between the two ratings by coder B were lower but still satisfactory ( $r=.73$ for WFS and $r=.87$ for DS); Cohen's $K$ was again high (at .95).

\section{Factorial Analysis and Internal Consistency}

The validity of grouping variables within protective versus risk category was studied first with a factorial analysis and second with Cronbach $\alpha$. The factorial analysis displayed a 2 -factor structure explaining $44.63 \%$ of the variance. The results supported our two subcategories conceptualizing risk factors and protection factors according to the child's or adolescent's development. The results of the factorial analysis as well as Cronbach $\alpha$ s are presented in Table 2. As expected, conflicting agents, conflict, negative outcomes, negative limits, negative emotions, content dynamics, closed system, and negative coalitions displayed positive loadings on the same dysfunctional factor. The other categories positive outcomes, positive limits, support, opened system, positive emotions, and positive coalitions loaded on the same well-functioning factor. Five crossloadings were displayed. Three of them were suitable with our expectations: Negative outcomes, positive outcomes, and positive emotions loaded on both factors but in the expected direction. However, the two others were unexpected: Closed system and positive limits loaded significantly and positively on both factors. The internal consistency was good for the risk factors but only moderate for the protection factors, respectively, $\alpha=.75$ and $\alpha=.53$.

The conceptual validity of the scales was also supported by the correlations among the 14 categories that are presented in Table 3. Positive significant correlations were observed among risk factors as well as among protective factors but to a lower
Table 2. Results of Exploratory Factor Analysis and Cronbach's $\alpha$ s

\begin{tabular}{lcc}
\hline & Risk Factors & Protective Factors \\
\hline Conflicting agents & .84 & \\
Conflicts & .84 & \\
Negative outcomes & .63 & -.54 \\
Negative emotions & .61 & \\
Negative limits & .57 & \\
Content dynamics & .47 & .42 \\
Closed system & .43 & \\
Negative coalitions & .39 & .54 \\
Positive outcomes & -.59 & .39 \\
Positive limits & .42 & .63 \\
Support & & .62 \\
Opened system & & .57 \\
Positive emotions & -.32 & .53 \\
Positive coalitions & & .53 \\
$\alpha$ & .75 & \\
\hline
\end{tabular}

extent. In addition, low and nonsignificant correlations were reported between risk and protective factors. DS and WFS were negatively significantly correlated at $-.29, p<.001$. Nevertheless, several unexpected correlations are displayed between closed system and opened system (.25), between closed system and positive coalitions (.16), and between opened system and content dynamics (.19). Positive limits are surprisingly positively correlated with risk factors whereas they are low correlated to protective factors.

\section{Discriminative Properties}

The discriminative properties of the revised FAT were assessed by comparing the scores of the clinical and the typical samples. Table 4 presents the means and standard deviations of the 14 variables, WFS, and DS for the paired samples. Paired $t$ tests revealed six significant differences for positive outcomes $(t(47)=-2.86, p<.01)$, positive limits $(t(47)=-2.30, p<$ $.05)$, negative outcomes $(t(47)=2.15, p<.05)$, negative emotions $(t(47)=-4.67, p<.001)$, closed system $(t(47)=-3.29$, $p<.01)$, and WFS $(t(47)=-2.01, p<.05)$. Participants in the clinical sample referred as expected to positive outcomes and positive limits less often, and to Negative outcomes more often on average than typical children and adolescents. In addition, their WFS was lower on average than the WFS of typical children and adolescents. Surprisingly, however, they referred less often, on average, to negative emotions and Closed System. Note that both the mean and standard deviation of the closed system category were at 0 in the clinical sample, meaning that none of the children and adolescents from this group refereed to this category. In sum, four of the differences were in the expected direction whereas two of those were not.

\section{Discussion}

This research has provided several modifications in the conceptual background, the administration, the coding procedure, and 
Table 3. Correlations Between Risk and Protective Factors

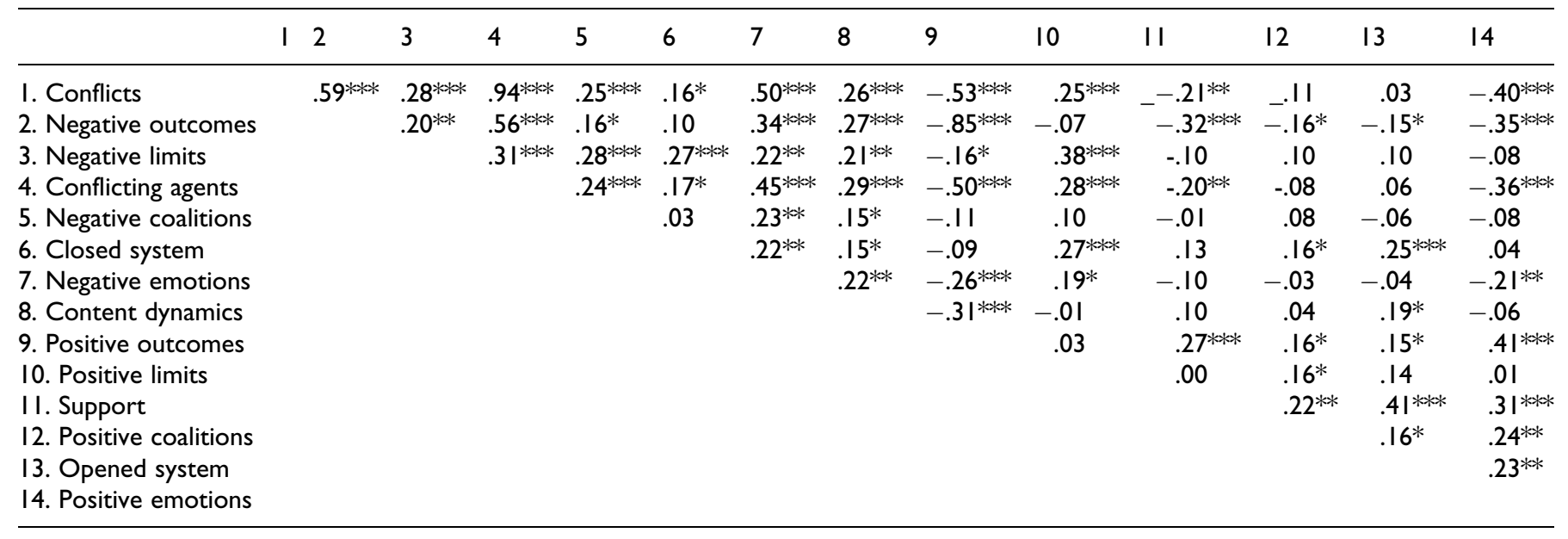

$* p<.05 . * * p<.01 . * * * p>.001$.

Table 4. Means (Standard Deviations) of the Protective and Risk Factors WFS and DS in the Typical and in the Clinical Paired Samples

\begin{tabular}{lcc}
\hline & Typical Sample, $N=48$ & Clinical Sample, $N=48$ \\
\hline Protective factors & & \\
Positive outcomes & $8.50(2.35)$ & $7.12(2.68)$ \\
Positive limits & $6.52(2.64)$ & $5.10(2.79)$ \\
Support & $4.48(2.64)$ & $4.27(3.51)$ \\
Positive coalitions & $0.52(0.79)$ & $0.39(0.79)$ \\
Opened system & $2.33(1.31)$ & $1.95(1.44)$ \\
Positive emotions & $4.87(2.66)$ & $4.89(3.15)$ \\
Risk factors & & \\
Conflicts & $6.45(1.84)$ & $6.58(2.97)$ \\
Negative outcomes & $2.56(1.98)$ & $3.60(2.87)$ \\
Negative limits & $1.31(1.11)$ & $0.85(0.82)$ \\
Conflicting agents & $6.85(2.08)$ & $7.23(3.33)$ \\
Negative coalitions & $0.23(0.51)$ & $0.25(0.52)$ \\
Closed system & $0.25(0.52)$ & $0.00(0.00)$ \\
Negative emotions & $10.87(3.36)$ & $7.58(3.77)$ \\
Content dynamics & $1.25(1.40)$ & $1.54(1.72)$ \\
Scores & & \\
WFS & $27.23(7.04)$ & $23.75(8.66)$ \\
DS & $29.79(9.19)$ & $27.64(12.52)$ \\
\hline
\end{tabular}

$* p<.05 . * * p<.01 . * * * p>.001$

the standardization of the FAT have been proposed. These modifications were intended to improve the instrument's psychometric properties, and the results indicate that in many ways they did. Inter-coder reliability ranged from .25 to .76 in previous studies. We reported better Cohen's $K$ coefficients for inter-coders reliability ranging from .91 to .98 as well as for intra-coders reliability, ranging from .73 to .99

Because the coding categories were split into two main groups, protective and risk factors, a factorial analysis was performed and the internal consistency of these 2 factors was estimated with Cronbach's $\alpha$ s. The results support the inclusion of the categories within the two main groups. Two categories, however, appeared to be problematic, closed system and positive limits. Both loaded positively on the risk and protective factors. In addition, they correlated both with risk and protective factors in a positive way. The closed system was defined as the prohibition or the restriction of exchangers between family members and the external world. It could be that the theoretical perspective that views such closeness as exclusively dysfunctional may be queried: restriction or prohibition of exchanges may well be appropriate, even healthy, in some temporary or specific family contexts (for example, to avoid negative influence of peers during adolescence).

The concept of limits was defined as rules or moral guidelines that have to be followed by the family members. They were considered positive if they promoted positive outcomes for the family members or if they did not hinder the family members in their development in case of adherence from the 
family members to these limits. On the contrary, they were also considered protective factors if they were inappropriate because they undermine the development of the family members, in case of explicit nonadherence from the family members. This last case could be responsible for the ambiguous results we obtained regarding positive limits as both a protective and a risk factor. Further development is needed to clarify the conceptual background of these two categories.

Regarding the conceptual background of other categories, progress was made in the definition of the coalitions. Indeed, in the revised test, we drew a distinction between Positive and Negative Coalitions, which did not exist in the original instrument. In the original version, coalitions were always regarded as negative relationships. Such a distinction seems to be meaningful from a statistical point of view and interesting from a qualitative point of view. Analyzing the participants' responses suggests that this distinction is essential for clinical interpretation. The correlations displayed in Table 3 indeed reveal some coherent family dynamics. Among the negative dynamics, negative coalitions are related to more conflicts, negative outcomes, negative limits, conflicting agents, negative emotions, and content dynamics. among the positive dynamics, positive coalitions are related to positive outcomes, positive limits, support, opened system, and positive emotions.

As earlier unpublished studies of conflicts and limits have indicated, some items on the FAT allow us to discriminate between typical children and those with clinical problems. As expected, responses concerning positive outcomes, positive limits, and WFS were higher in the typical than in the clinical sample whereas the negative outcomes were lower in the typical than in the clinical sample. Surprisingly, however, responses concerning closed system and negative emotions were less frequent in the clinical than in the typical sample. This may be due, especially for the closed system, to the low number of times these responses occurred, as shown in Table 4. Another reason may lie in the composition of the clinical sample who were recruited from two different clinical units. Participants from the Cliniques Universitaires Saint-Luc were ambulatory and were being counseled by clinicians for diverse scholastic, behavioral, or emotional problems. They still lived within their family environment. However, the participants from the Institut Louis Marie were adolescents with behavioral disorders and psychotic personalities who were institutionalized during the week and only living in their family environments at the weekends. The first group was closer to the typical sample than the second one, implying certain heterogeneity in the clinical sample. This may explain to some extent the unexpected results in the comparative analyses.

In conclusion, we feel that the modifications to the conceptual background, the administration, the coding procedure, and the standardization of FAT improve its psychometric properties. The revised version of FAT removes many of the previous weaknesses in projective techniques and family assessment and should be used both in clinical and research programs. However, some questions and limitations remain. Closed system and positive limits remain less valid than the other categories. Other limitation of the current study concerns the number of participants in the sample, which could lead to bias. Small sample sizes increase the frequency of convergent failure and failure to replicate findings. This is particularly true for the clinical sample. Our results should be interpreted with caution until the findings have been replicated on a larger sample. Moreover, because our clinical sample suffers from heterogeneity, with some participants too similar to typical children, the results should be replicated on a homogeneous clinical sample whose characteristics differ markedly from the typical sample. Finally, our data does not allow us to determine whether the reduction from 21 to 10 or 12 pictures has enhanced the validity of the measure. Another study is needed to compare these two administrative procedures.

In sum, the coding categories which were presented here have to be considered as guidelines for clinicians to understand the subject's family relationships. However, the clinical competence of the psychologist remains essential for elaborating interpretations and for directing the therapeutic process. Several clinical questions were addressed by the authors of the original test, which are intended to guide the qualitative analysis. These questions are still of great interest for the clinician beyond the categories presented here. The FAT is characterized by a complementary view - both quantitative and qualitativeof children and their families.

\section{Declaration of Conflicting Interests}

The author(s) declared no potential conflicts of interests with respect to the authorship and/or publication of this article.

\section{Funding}

The author(s) received no financial support for the research and/or authorship of this article. 


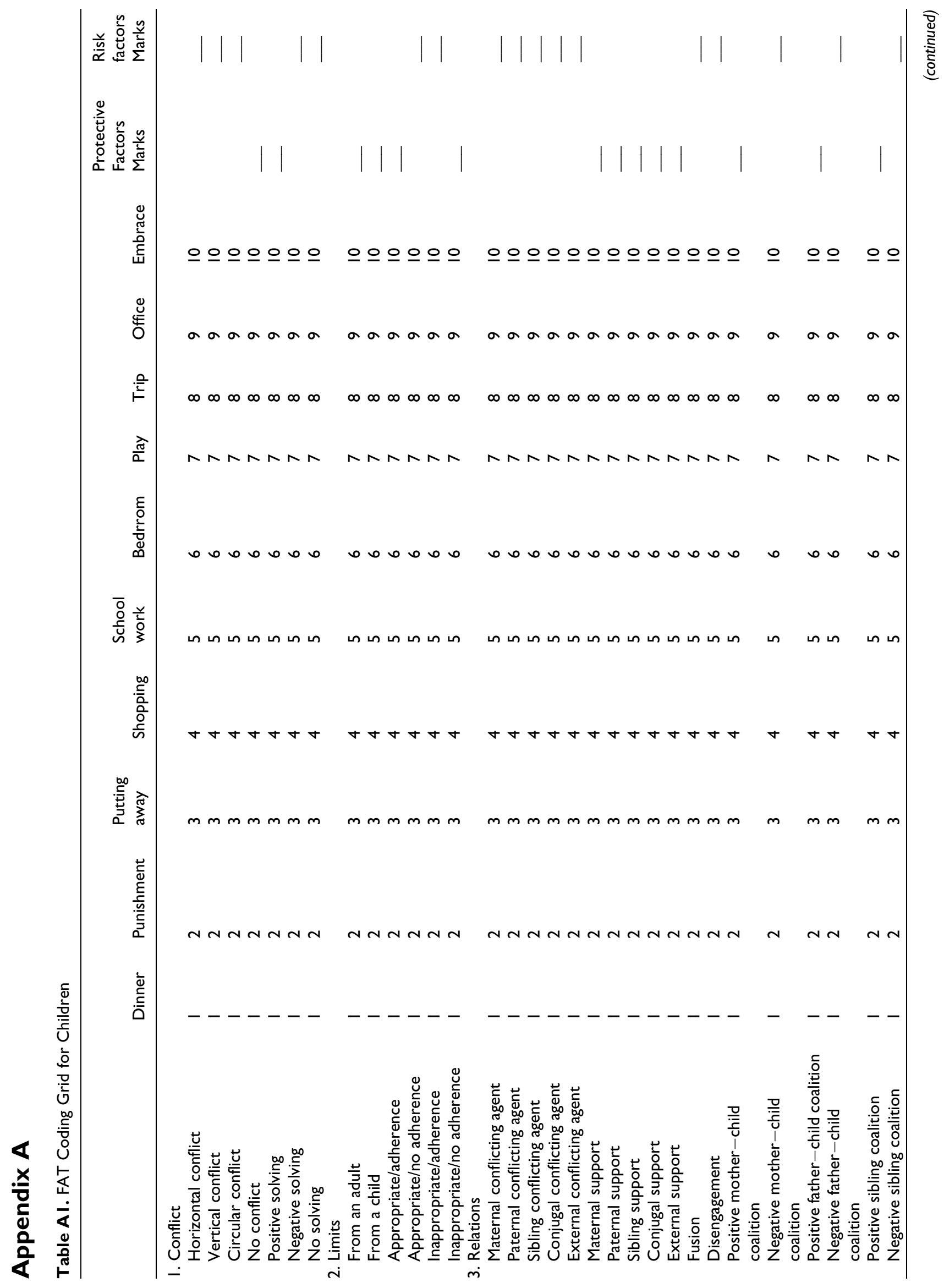




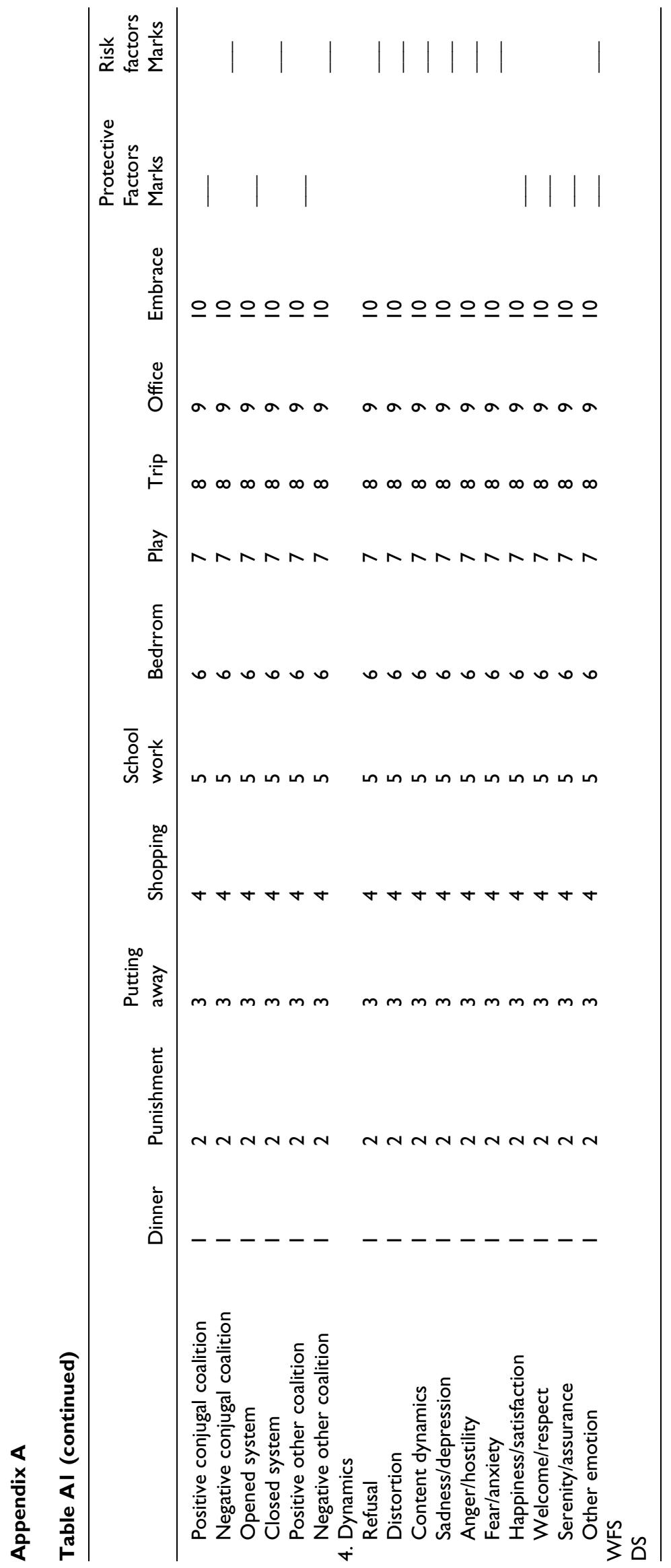




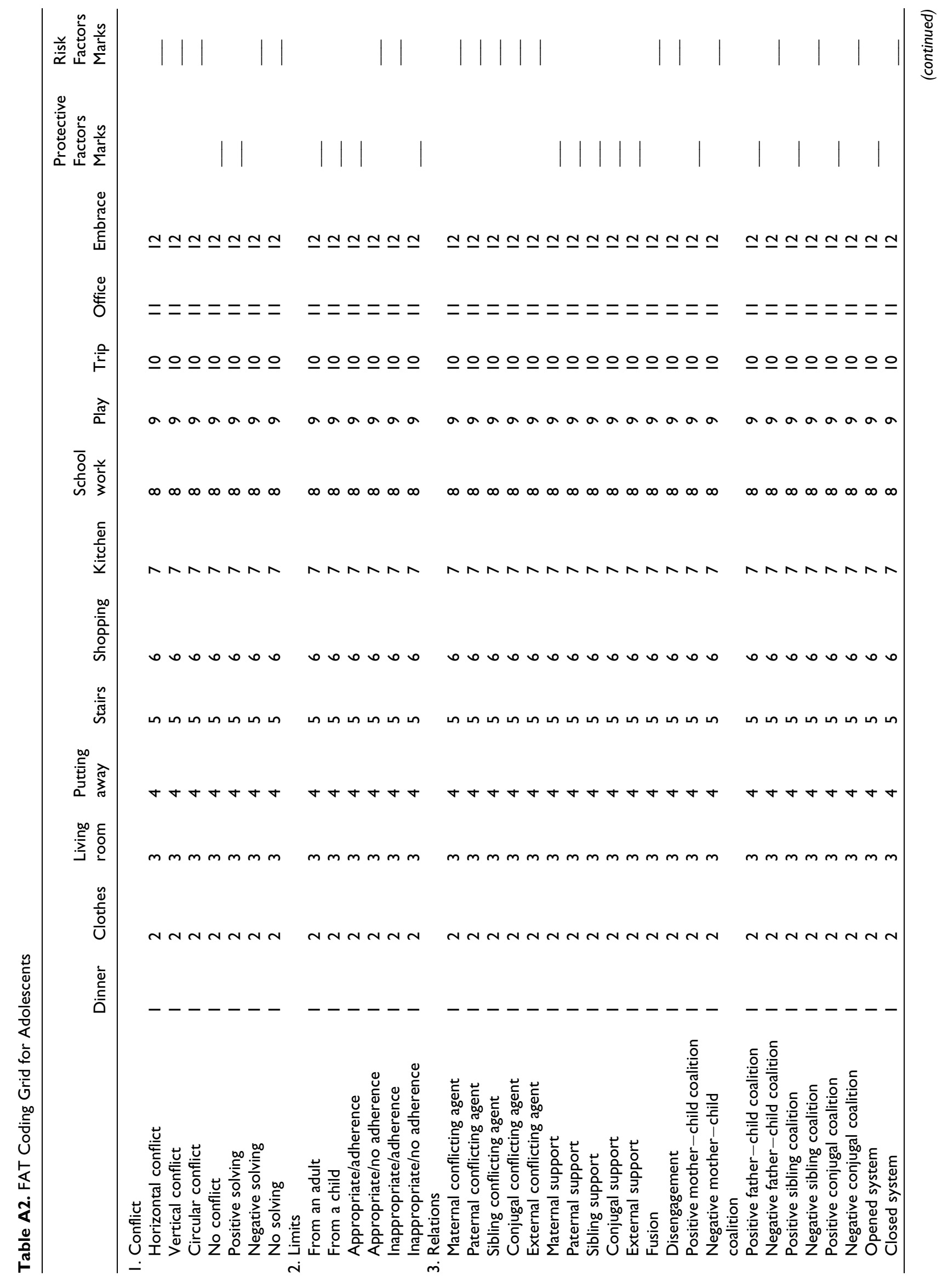




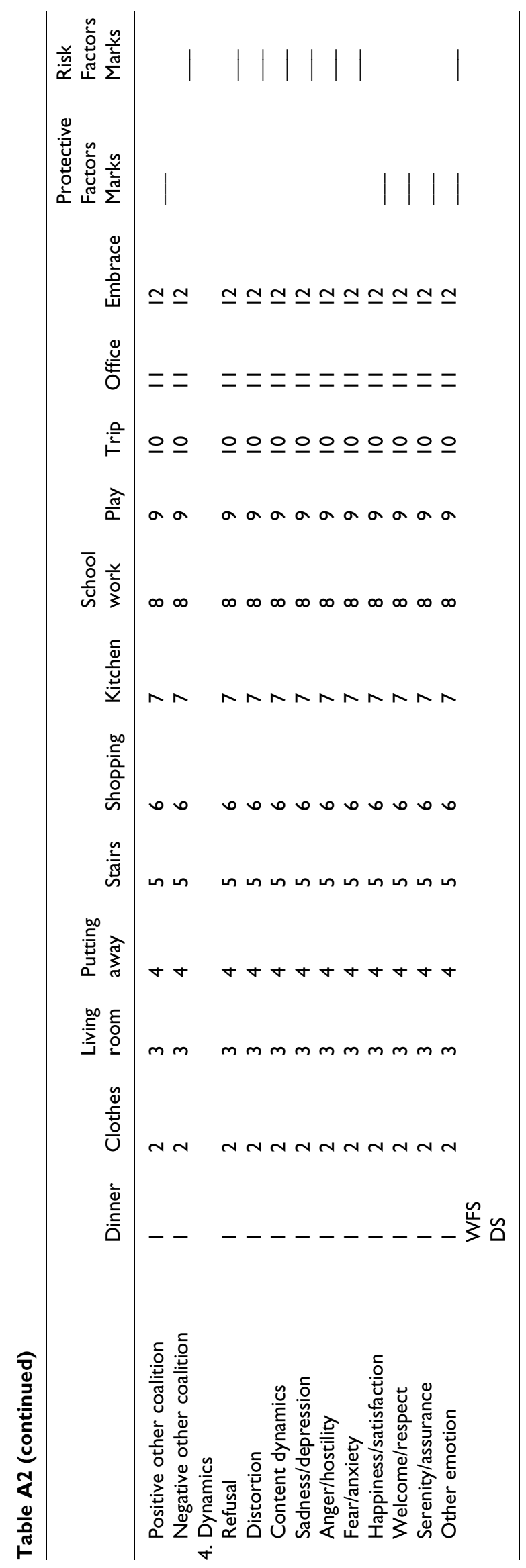




\section{References}

Anderson, H., \& Anderson, G. (1965). Manuel des techniques projectives en psychologie clinique. Paris, France: Editions Universitaires.

Anzieu, D., \& Chabert, C. (1999). Les méthodes projectives. Paris, France: Presses Universitaires de France.

Aunola, K., \& Nurmi, J. E. (2005). The role of parenting styles in children's problem behavior. Child Development, 76, 1144-1159.

Ball, J., Archer, R., Gordon, R., \& French, J. (1991). Rorschach Depression indices with children and adolescents: Concurrent validity findings. Journal of Personality Assessment, 57, 465-476.

Barber, B., \& Buelher, C. (1996). Family cohesion and enmeshment: Different constructs, different effects. Journal of Marriage and the Family, 58, 433-441.

Beavers, W. R., Hampson, R. B., \& Hulgus, Y. S. (1990). Beavers systems model: Observational and self-report scale. Dallas, TX: Southwest Family Institute.

Bellak, L., \& Bellak, S. (1949). Children's Apperception Test. Oxford, England: C.P.S.

Bene, E. (1965). Manual for the adult version of the Family Relations Test. Berkshire, England: NFER-Nelson Publishing Company.

Bergeron, L., \& Valla, J. (1997). Facteurs de risque et de protection d'ordre environnemental. In Dans V. Kovess (Ed.), Troubles dépressifs chez l'enfant. Paris, France: Frison-Roche.

Branje, S., van Lieshout, C., \& van Aken, M, \& Haselager, G. (2004). Perceived support in sibling relationships and adolescent adjustment. Journal of Child Psychology and Psychiatry, 45, 1385-1396.

Buchanan, S. M. (1999). A comparison of clinic and non-clinic children on the family apperception test. In Sotile, W., Julian, A., Henry, S., \& Sotile, M. (Eds.), Family Apperception Test: Manuel. Paris, France: Les Editions du Centre de Psychologie Appliquée.

Campbell, S., Pierce, E., Moore, G., \& Marakowitz, S. (1996). Boys' externalising problems at elementary school age: Pathways from early behaviour problems, maternal control, and family stress. Development and Psychopathology, 8, 701-719.

Carter, C. \& Dacey, C. (1996). Validity of the Beck Depression Inventory, MMPI and Rorschach in assessing adolescent depression. Journal of Adolescence, 19, 223-231.

Caya, M. (2002). Sibling support and sibling attachment: Promoting the adjustment of children in high conflict families. Dissertation Abstracts International: Section B: The Sciences and Engineering, 62,5366

Corman, L. (1970). Le test du Dessin de la famille. Paris, France: Presses Universitaires de France.

Cuffe, S., McKeown, R., Addy, C., \& Garrison, C. (2005). Family and psychosocial risk factors in a longitudinal epidemiological study of adolescents. Journal of the American Academy of Child and Adolescent Psychiatry, 44, 121-129.

Daure, I. (2001). Family relationships: Support for psychotic adolescent's treatment. Psicologia Clinica, 13, 73-84.

Davies, P. (1996). Children's emotional security as a mediator of the link between marital conflict and child adjustment. Dissertation Abstracts International: Section B: The Sciences and Engineering, 57, 4053.

DeChatelet, M. P. (1999). A study of the interrater reliability of the family apperception test utilizing three raters. In Sotile, W., Julian, A.,
Henry, S., \& Sotile, M. (Eds.), Family Apperception Test: Manuel. Paris, France: Les Editions du Centre de Psychologie Appliquée.

Donleavy, G., \& Lim, A. (1990). Cross cultural validation of the TAT (Pilot phase of a project to test the Atkinson Model). Assessment and Evaluation in Higher Education, 15, 1-11.

Eaton, C. B. (1988). The family apperception test: A study of the construct validity of a long and short form. In Sotile, W., Julian, A., Henry, S., \& Sotile, M. (Eds.), Family Apperception Test: Manuel. Paris, France: Les Editions du Centre de Psychologie Appliquée.

Eysenck, H. (1955). La validité des techniques projectives. Revue de Psychologie Appliquée, 5, 231-233.

Garb, H., Florio, C., \& Grove, W. (1998). The validity of the Rorschach and the Minnesota Multiphasic Personality Inventory: results from meta-analyses. Psychological Science, 9, 402-404.

Gehring, T. M., \& Debry, M. (1992). Evaluation du système familial: FAST. Braîne-le-Château: Application des techniques modernes, Sprl.

Geuzaine, C. (2003). Intimacy: Between fusion and distance. Bulletin de Psychologie, 56, 345-356.

Gingrich, N. E. (1999). Interrater reliability of the family apperception test. A preliminary study. In Sotile, W., Julian, A., Henry, S., \& Sotile, M. (Eds.), Family Apperception Test: Manuel. Paris, France: Les Editions du Centre de Psychologie Appliquée.

Gjerde, P. F., Block, J., \& Block, J. H. (1983). Parental interactive patterns in dyads and triads: Prospective relationships to adolescent personality characteristics. Unpublished manuscript.

Grant, M., Ives, V., \& Ranzoni, J. (1952). Reliabililty and validity of judges'rating of adjustment on the Rorschach. Psychological Monographs, 66, 20.

Gronnerod, C. (2003). Temporal stability in the Rorschach method: A meta-analytic review. Journal of Personality Assessment, 80, 272-293

Henry, W., \& Farley, J. (1959). The validity of the Thematic Apperception Test in the study of adolescent personality. Psychological Monographs, 73, 40.

Jackson, L. (1952). A test of family attitudes. New York: Methuen.

Janson, H., \& Stattin, H. (2003). Prediction of adolescent and adult delinquency from childhood Rorschach ratings. Journal of Personality Assessment, 81, 51-63.

Jenkins, J., Simpson, A., Dunn, J., Rasbash, J., \& O’Connor, T. (2005). Mutual influence of marital conflict and children's behavior problems: shared and nonshared family risks. Child Development, 76, 24-39.

Jewell, J., \& Stark, K. (2003). Comparing the family environments of adolescents with conduct disorder or depression. Journal of Child and Family Studies, 12, 77-89.

Lisansky, E. (1956). The inter-examiner reliabililty of the Rorschach test. Journal of Projective Techniques, 20, 310-317.

Lundquist, A. (1999). A projective approach to family systems assessment: A preliminary validity study of the family apperception test. In Sotile, W., Julian, A., Henry, S., \& Sotile, M. (Eds.), Family Apperception Test: Manuel. Paris, France: Les Editions du Centre de Psychologie Appliquée.

Mathijsen, J., Koot, H., Verhulst, F., De Bruyn, E., \& Oud, J. (1998). The relationship between mutual family relations and child psychopathology. Journal of Chil Psychology and Psychiatry and Allied Disciplines, 39, 477-487. 
Meyer, G., Mihura, J., \& Smith, B. (2005). The interclinician reliability of Rorschach interpretation in four data sets. Journal of Personality Assessment, 84, 296-314.

Moos, R., \& Moos, B. (1986). Family Environment Scale: Manual (2nd ed.). Palo Alto, CA: Consulting Psychologists Press.

Moritzen, S. (2003). The relationship between spouses'conflict management behaviours, spousal support, and spousal negativity, and their children's social competence. Dissertation Abstracts International: Section B: The Sciences and Engineering, 63, 4420.

Murray, H. (1943). Thematic apperception test. Cambridge, MA: Harvard University Press.

Niggemeyer, H. A. (2001). Family interaction factors and anxiety in adolescent females. Dissertation Abstracts International: Section B: The Sciences and Engineering, 62, 1592.

Parker, K. (1983). A meta-analysis of the reliability and validity of the Rorschach. Journal of Personality Assessment, 47, 227-231.

Parker, K., Hanson, T., \& Hunsley, J. (1988). MMPI, Rorschach and WAIS: A meta-analytic comparison of reliability, stability and validity. Psychological Bulletin, 103, 367-373.

Perosa, L., Hansen, J., \& Perosa, S. (1981). Development of the Structural Family Interaction Scale. Family Therapy, 8, 77-90.

Rasmussen, K. (1995). Parental control and adolescent aggression, delinquency, self-derogation, and suicidal ideation. Dissertation Abstracts International: Section B: The Sciences and Engineering, 55,3574 .

Rodriguez, C. M. (2003). Parental discipline and abuse potential affects on child depression, anxiety and attributions. Journal of Marriage and Family, 65, 809-817.
Rorschach, H. (1921). Psychodiagnostics: A diagnostic test based on perception. (3rd ed. rev.). Oxford, England: Grune and Stratton.

Sigfusdottir, I., Farkas, G., \& Silver, E. (2004). The role of depressed mood and anger in the relationship between family conflitct and delinquent behavior. Journal of Youth and Adolescence, 33, 509-522.

Skinner, H., Steinhauer, P., \& Santa-Barbara, J. (1983). The family assessment measure. Canadian Journal of Community Mental Health, 2, 91-105.

Smilkstein, G. (1978). The Family APGAR: A proposal for family function test and its use by physicians. The Journal of Family Practice, 6, 1231-1239.

Sotile, W., Julian, A., Henry, S., \& Sotile, M. (1999). Family Apperception Test: Manuel. Paris, France: Les Editions du Centre de Psychologie Appliquée.

Steinberg, L., Lamborn, S., Darling, N., Mounts, N., \& Dornbusch, S. (1994). Over-time changes in adjustment and competence amount adolescents from authoritative, authoritarian, indulgent, and neglectful families. Child Development, 65, 754-770.

Tucker, C., McHale, S., \& Crouter, A. (2003). Conflict resolution: links with adolescents' family relationships and individual wellbeing. Journal of Family Issues, 24, 715-736.

Weiner, I. B. (2000). Making Rorschach interpretation as good as it can be. Journal of Personality Assessment, 74, 164-174.

Weiner, I. B. (2003). The assessment process. In J. A. Naglieri, \& J. R. Graham (Eds.), Handbook of psychology: Assessment psychology (Vol.10, pp. 3-25). Hoboken, NJ: John Wiley.

Zubin, J., Eron, L. D., \& Schumer, F. (1965). An experimental approach to projective techniques. New York, NY: John Wiley. 